\title{
Um estudo sobre a morte: uma análise a partir do método explicativo de Vigotski
}

\author{
A study on death: \\ an analysis based on Vigotski's dialectical method
}

Denise Stefanoni Combinato ${ }^{1}$

Marcos de Souza Queiroz ${ }^{2}$

${ }^{1}$ Instituto Tecnológico de Aeronáutica. Praça Marechal Eduardo Gomes 50 , Vila das Acácias. 12228-900 São José dos Campos SP. denisecombinato@hotmail.com ${ }^{2}$ Faculdade de Ciências Médicas, Unicamp
Abstract This article focuses on the concept of death and, in particular, the social construction of its meaning for a professional healthcare team working in an intensive hospital care unit. Thirteen professionals (six physicians and seven nurses) participated in the research, through semistructured interviews. Despite the fact that death is part of the human cycle and is present in the daily working life of these health professionals, the denial of its existence imposed by the culture of the modern western world prevents the development of specific strategies to address this problem. Based on the Vigotski's dialectical method, three main conceptions of death were extracted from the interviews: death as a natural consequence of life; death as a biological process and death as a divine blessing. In the absence of a proper space for a more systematical approach, the social representations from the professionals on this theme are restricted to subjective opinions. In the conclusion, the need for change in the institutional context and in health education is emphasized, with a specific focus directed on death and on the process of dying.

Key words Representations on death, Health professionals and death, Social representations, Vigotski
Resumo Este artigo focaliza a concepção de morte em geral e, especificamente, a construção social de seu significado por uma equipe de profissionais da saúde, que trabalha em uma unidade hospitalar de cuidado intensivo. Participaram desta pesquisa, através de entrevista individual semiestruturada, treze profissionais (seis médicos e sete enfermeiros). Ainda que a morte seja parte do processo de desenvolvimento humano e esteja presente na vida cotidiana de profissionais da saúde, a negação da sua existência imposta pela cultura do mundo ocidental moderno impede que se desenvolvam estratégias específicas de enfrentamento deste problema. A partir do método explicativo de Vigotski, das entrevistas, foram extraídas e analisadas três principais concepções de morte: como consequência da vida; como processo biológico e como bênção divina. Sem haver um campo apropriado para o desenvolvimento mais sistemático do tema, as representações dos profissionais sobre o assunto permanecem restritas a um nível subjetivo. Na conclusão, é enfatizada a necessidade de mudança no contexto institucional e na educação em saúde, com um foco mais específico na morte e no processo de morrer.

Palavras-chave Representações sobre morte, Profissionais da saúde e morte, Representações Sociais, Vigotski 


\section{Introdução}

A morte compõe o processo de desenvolvimento humano e está presente no cotidiano dos profissionais da saúde. Apesar disso, a cultura ocidental moderna nega sua existência ${ }^{1,2}$ e traz como paradigma científico o modelo biomédico, imprimindo uma separação radical tanto entre o doente e a doença como entre a vida e a morte.

Mesmo estabelecendo esta cisão, não se pode negar que a morte continua sendo um tema complexo para o ser humano, suscitando questões existenciais sobre o sentido da vida e o porquê da morte; além de instigar, numa sociedade medicalizada que pôs fim à morte natural, o desenvolvimento de estudos e pesquisas que prolonguem a vida ou promovam a possibilidade utópica de imortalidade do homem ${ }^{3,4}$.

Neste artigo, focalizamos a complexidade do tema para profissionais da saúde que trabalham em Unidades de Terapia Intensiva. Considerando que desenvolvem sua atividade profissional em um espaço onde a presença da morte é constante, e que tanto a cultura ocidental como o paradigma científico em que foram formados impõem uma ruptura entre vida e morte, razão e afeto, levantamos as seguintes questões: como tais profissionais entendem e lidam com o processo de morte? De que maneira a formação profissional contribuiu ou poderia contribuir com a compreensão e o enfrentamento de situações relacionadas à morte na UTI?

A análise do fenômeno psicológico, de acordo com o método explicativo de Vigotski ${ }^{5}$, caracteriza-se pela compreensão do processo histórico e social que constitui o fenômeno em estudo; pela busca da sua essência, a fim de conhecer sua gênese e suas relações dinâmico-causais; pela captação do movimento, das contradições e da transformação do objeto de estudo. Tais aspectos têm como finalidade a compreensão do fenômeno psicológico em sua totalidade.

Vigotski ${ }^{5}$ propõe como método de análise psicológica a utilização de unidades de análise. Tal perspectiva conserva uma noção de totalidade, ao contrário do que ocorre com o método de decomposição em elementos. De acordo com o autor, o primeiro método possui todas as propriedades que são inerentes ao todo e, concomitantemente, são partes vivas e indecomponíveis dessa unidade. Já o método da decomposição em elementos propicia a obtenção de produtos heterogêneos ao todo analisado, que não contêm as propriedades inerentes ao todo como tal e que possuem uma variedade de propriedades que nunca poderiam ser encontradas nesse todo.
Para exemplificar, Vigotski ${ }^{5}$ recorre à análise da composição química da água: se fizermos a decomposição em elementos, teremos dois elementos químicos (hidrogênio e oxigênio), com propriedades distintas às da água; ou seja, a análise isolada de cada elemento não conserva nas suas partes, as propriedades da totalidade. Por isso, ele sugere a análise da água a partir do estudo das moléculas e movimento molecular, e não pela composição química. Da mesma maneira, a unidade de análise que contém todas as propriedades do pensamento verbalizado é encontrada no significado da palavra 5 .

A partir, então, do método da análise semântica ou do significado da palavra, utilizamos duas categorias psicossociais nesta pesquisa: representação social e consciência.

A representação social, na perspectiva da psicologia sócio-histórica, é uma expressão da consciência. A consciência é uma categoria psicossocial de análise do fenômeno psicológico, definida por Leontiev ${ }^{6}$ como sendo o reflexo da realidade, refratada através do prisma das significações e dos conceitos linguisticos, elaborados socialmente.

Dessa maneira, pensar em consciência implica pensar no modo de vida, na evolução e na existência humana; nas condições sociais e históricas que se formam e constituem as relações vitais do homem; além das estruturas que envolvem tais relações e no modo como a atividade influencia o desenvolvimento e a transformação da consciência.

Para se ter o conhecimento concreto da consciência, utiliza-se as representações sociais que são as expressões mais imediatas de seus conteúdos. Ou seja, a representação social constitui-se em um dado empírico do qual se parte para uma análise dialética, que permite conhecer concretamente a consciência, a atividade e a identidade de sujeitos situados social e historicamente ${ }^{7}$.

É importante ressaltar que a consciência está em constante (trans) formação a partir do contexto sócio-histórico em que a pessoa está inserida. Portanto, a representação social enquanto expressão empírica da consciência retrata um momento desse processo, que necessariamente está relacionada à situação que a envolve.

Com base nesse referencial, discutiremos a concepção de morte para profissionais da saúde que trabalham em uma UTI, tendo em vista a compreensão do processo de construção e o contexto em que ela se tornou prevalente; além das contradições e transformações ocorridas, procurando apreender essa concepção em sua totalidade. 
O local de coleta de dados foi um hospital de médio a grande porte localizado no interior do Estado de São Paulo, com credenciamento de Unidade de Terapia Intensiva (UTI) para atendimento a população adulta. Após autorização da diretoria do hospital para o desenvolvimento da pesquisa em uma UTI e aprovação do Comitê de Ética em Pesquisa em consonância com a Resolução $196 / 96^{8}$, todos os médicos e enfermeiros que exerciam suas atividades naquela unidade foram convidados a participar da pesquisa, totalizando nove médicos e oito enfermeiros. Aceitaram participar seis médicos e sete enfermeiros que serão apresentados neste artigo por letras (E: enfermeiro; M: médico) e números atribuídos aleatoriamente.

\section{Método}

O tema do presente estudo exigiu uma aproximação metodológica essencialmente qualitativa, uma vez que se trata de uma perspectiva que privilegia a profundidade das informações em detrimento da sua extensão e rigor quantitativo. Nesse sentido, o campo de investigação inicia-se com o pressuposto de que os sujeitos entrevistados têm representações relativamente coerentes em relação ao universo vivido e experimentado. Trata-se de um conhecimento prático, de senso comum, baseado na experiência de vida e de atuação, que gera concepções e diagnósticos sobre os problemas encontrados, ao mesmo tempo em que orienta e propõe intervenções mais eficazes na realidade.

Os dados foram coletados no período de dezembro/2003 a fevereiro de 2004, através de entrevista individual semiestruturada, gravada em fita cassete, mediante autorização e assinatura do Termo de Consentimento Livre e Esclarecido. As entrevistas foram conduzidas no próprio local de trabalho, em uma sala que permitiu isolamento da rotina de trabalho. Em média, elas duraram cerca de duas horas, sendo que, para esclarecimentos de questões pontuais, houve retorno em outras ocasiões.

A pesquisa utilizou também o método da observação participante (Malinowski ${ }^{9}$ ), que permitiu que a pesquisadora pudesse passar vários momentos, principalmente antes do período das entrevistas, em contato com a rotina do hospital. As impressões colhidas nestas ocasiões foram anotadas como um diário de campo, o que contribuiu para a formulação das questões levantadas nas entrevistas.
Após a transcrição das entrevistas, o procedimento de análise compreendeu os seguintes passos: leitura flutuante do material coletado; categorização das respostas; definição da unidade de análise a partir do método proposto por Vigotski; busca da essência ou do sentido das respostas apresentadas; articulação das respostas com variáveis psicossociais, formação profissional e contexto cultural.

\section{Resultados}

A idade dos participantes encontra-se entre $24 \mathrm{e}$ 48 anos, sendo a média de 33,2 anos. O tempo de serviço na profissão é relativamente pequeno. A maioria exerce sua atividade entre um e três anos (sete profissionais) e apenas três profissionais estão nas atuais atividades há mais de dez anos. A maioria dos profissionais fez ou está fazendo pós-graduação (residência, especialização ou mestrado) e está vinculada a mais de um local de trabalho.

Para iniciar a nossa análise, selecionamos, abaixo, alguns relatos dos participantes quando se referem à concepção que têm sobre a morte:

Eu acho que a morte é uma consequência natural da vida. Desde que nós nascemos nós estamos morrendo. Só que ninguém encara isso naturalmente E1

Eu não acho fácil falar sobre isso [morte], talvez pelo medo de não saber o que vem depois [...] Você morre e acabou? Então eu não encaro a morte com tranquilidade [...] Dá aquela sensação de impotência, sabe? E5

Perda! Tristeza! Saudade! Medo da morte eu tenho; não da morte dos outros, né? Tenho medo da morte minha e da minha filha, né? M3

Eu não sei dizer pra você o significado da morte [...] A gente consegue defini-la tecnicamente, mas o que ela significa eu não sei dizer [...] Pra mim, a morte é o fim da vida e, em alguns casos é, para mim como médico, um fracasso da minha parte M5

Percebe-se nesses relatos que vários aspectos em relação à concepção de morte são apontados: morte como processo natural; dúvida sobre o que vem depois da morte; impotência do profissional diante da morte; morte como perda, separação; medo da morte; morte como processo técnico.

$\mathrm{Na}$ aparência do fenômeno ou na representação mais imediata, verifica-se a dificuldade dos participantes para falar sobre a morte. Quando não verbalizaram, demonstraram como é peno- 
so falar sobre a morte através de expressões corporais e emocionais. Além disso, destaca-se que os profissionais manifestaram ter dificuldade para lidar com pacientes, familiares e/ou com seus próprios sentimentos e emoções diante do processo de trabalho que envolve a terminalidade da vida.

A partir do método de análise semântica e da leitura exaustiva das entrevistas, sugere-se como unidade de análise a finitude do ser humano enquanto fim da condição humana para determinado indivíduo; ou o fim das suas funções encefálicas, sociais e psíquicas. Assim, a partir e em relação a essa unidade de análise, avaliarems três principais concepções de morte: a morte como consequência da vida; a morte como processo biológico e a morte como bênção divina.

A morte como consequência da vida referese inicialmente à naturalidade deste fenômeno:

[a morte] é uma consequência pra mim. Eu já tive muitos dramas de consciência de perder paciente. Hoje não. Hoje eu chego à conclusão que a morte é uma consequência da vida M2

Se a nossa proposta, a partir do método de análise proposto por Vigotski, é ir além da aparência do fenômeno, então é preciso entender cada concepção na sua essência, buscando a historicidade, explicações e contradições.

Procurando esse entendimento, destaca-se que a morte foi considerada por nossos entrevistados como algo muito mais abrangente e complexo do que uma simples consequência da vida. Neste espaço, a morte adquire sentidos subjetivos que dependem da influência cultural, do meio social e do mundo psíquico de cada indivíduo.

Para entender tal sentido, é preciso compreender o motivo que o originou. Nas palavras de Vigotski ${ }^{5}$, para entender o discurso do outro, nunca é necessário entender apenas umas palavras; precisamos entender o seu pensamento. Mas é incompleta a compreensão do pensamento do interlocutor sem a compreensão do motivo que o levou a emiti-lo.

Segundo o autor, o sentido é um fenômeno complexo, podendo destoar da palavra expressa ou ser fixado a uma outra palavra, por exemplo. Por isso, para captar o verdadeiro sentido é preciso compreender a riqueza dos momentos existentes na consciência e relacionados àquilo expresso por uma determinada palavra.

Para M2, a morte é natural desde que aconteça na ordem natural: primeiro, o mais velho e, depois, o mais novo.

Hoje em dia eu acho que eu não suportaria perder um filho. A mãe, o pai é uma coisa que eu sei que vai acontecer. Eu acho que a ordem natural é essa. Você perder o mais velho e não o mais novo M2

Além disso, a morte é considerada natural ou aceitável desde que sejam de pessoas idosas e/ou pacientes com doenças crônicas que passem por grande sofrimento, que não apresentam qualidade de vida e/ou não tenham perspectiva de vida saudável. Para os profissionais (E1, E2, E6, M2 M4, M6), esse tipo de morte é, inclusive, um alívio.

Por outro lado, quando morre um paciente jovem ou quando acontece uma morte súbita, é difícil aceitar. Coerente com a expectativa da sociedade capitalista, em cujo contexto ocorre uma supervalorização dos jovens, a perda dessas pessoas significa a perda de indivíduos economicamente ativos. Esta situação é oposta à perda de pessoas idosas, que não produzem mais e geram custos elevados para a manutenção de suas vidas. Nesta última situação, perde-se a dimensão do quanto a pessoa idosa já produziu e investiu no desenvolvimento da sociedade. Ela torna-se, literalmente, um encargo.

Assim, dependendo da causa e da circunstância em que ocorre a morte - morte súbita ou decorrente de uma doença crônica e degenerativa, por exemplo - considera-se mais fácil ou mais difícil de lidar. Esses dados encontram fundamentação na literatura científica nos casos de morte em que envolvem vínculo afetivo, mas que podem ser utilizados nessa análise. Para Kovács ${ }^{10}$, quando a morte é súbita e inesperada, gera nos outros indivíduos desorganização, paralisação $e$ impotência, podendo dificultar o processo de luto. Já no caso de morte com pacientes gravemente enfermos, ocorre um processo denominado de luto antecipatório, ou seja, o processo de luto inicia-se antes mesmo da morte, sendo antecipada a elaboração da perda. A autora refere que esses casos podem gerar sentimentos ambivalentes naqueles que cuidam (nesse caso específico, a família): desejo de que a pessoa morra para aliviar o sofrimento de ambos e, ao mesmo tempo, sentimento de culpa por ter tal desejo.

A morte também é considerada natural desde que seja com pessoas com quem não se tem vínculo afetivo:

Com a outra pessoa, com o desconhecido, você até fica tocada. Mas conforme o tempo vai passando, você aprende a se pôr atrás de uma redoma [...] Você aprende a ficar distante E4

Mas, quando se trata de alguém com quem se tinha vínculo afetivo, E4 resume a opinião de vários profissionais (E1, E4, E7, M2, M3, M6) ao afirmar que quando é alguém seu, é complicado! Aíé outra história. Segundo Kovács ${ }^{10}$, ocorre nesse 
caso a vivência da morte em vida. Isso significa que ocorre a possibilidade de experiência da morte que não é a própria, mas é vivida como se uma parte nossa morresse, uma parte ligada ao outro pelos vínculos estabelecidos. Assim, a morte configura-se como uma perda, visto que envolve a relação afetiva entre pessoas.

No caso de morte de pessoas desconhecidas, o profissional pode refletir sobre sua existência, seu envelhecimento e, principalmente, sua finitude. Tal reflexão pode gerar um processo de ressignificação da vida e de transformação das relações estabelecidas com o viver. No entanto, se essa reflexão provocar angústias, é mais fácil distanciar-se. $\mathrm{O}$ questionamento que fazemos neste caso é: se o profissional distancia-se das reflexões desencadeadas pela morte do outro, como pode lidar com o paciente sem possibilidades terapêuticas? ${ }^{11}$

Em resumo, embora na aparência do fenômeno o significado de morte esteja relacionado a um processo natural, quando se busca sua essência, percebe-se que a compreensão da morte como consequência da vida acontece desde que a morte ocorra na ordem natural (os mais velhos e não os mais novos); com pacientes idosos ou com doenças crônicas (e não jovens) e com quem não se tenha vínculo afetivo. Quando isso não acontece, a finitude de ser humano como processo natural é substituída por perda (não suportaria perder um filho - M2) e negação da morte (ninguém quer morrer - E2).

A negação da morte pode se relacionar a uma segunda concepção: a morte como processo biológico:

A morte é o término das funções vitais, das funções encefálicas de um doente M5

Embora M5 saiba que a morte é muito mais abrangente do que isso, ele não consegue defini-la de outra maneira: eu não sei dizer.

Isso porque a formação técnica em saúde, em geral, nega a possibilidade de morte e afirma ser função do profissional da saúde não o cuidado do paciente, mas a recuperação e manutenção da vida a qualquer custo.

Todo mundo foi treinado pra salvar vidas e simplesmente fingir que não existe a morte M2

Os cursos de formação na área da saúde principalmente os de enfermagem e de medicina - caracterizam-se pela ênfase nos procedimentos técnicos em detrimento de uma formação hu$\operatorname{mana}^{12,13}$.

Todos os participantes dessa pesquisa avaliaram que tiveram uma boa formação teórico-técnica na graduação. Entretanto, a maioria revela não ter aprendido habilidades interpessoais, presentes nas ciências humanas, embora tais habilidades - juntamente com os conhecimentos teórico-técnicos - sejam consideradas necessárias para o desenvolvimento da atividade profissional. Apenas M2 e M3 citaram os conhecimentos teórico-técnicos como os únicos necessários para o desenvolvimento da atividade médica.

Se o ensino de habilidades interpessoais é bastante negligenciado (M6), o que dizer do ensino sobre o processo de morte? De acordo com Meleiro ${ }^{14}$ o profissional da saúde está preparado para a cura, mas frequentemente angustiado pela morte.

Nessa pesquisa, os dois médicos com maior tempo de formação não tiveram disciplinas na grade curricular que abordassem temáticas relacionadas à morte. $\mathrm{O}$ que eles tiveram, nesse sentido, foi baseado no modelo de combate à morte.

Já os profissionais que se formaram mais recentemente tiveram formação sobre o assunto. No entanto, na grande maioria dos casos, ela foi considerada insatisfatória, não conseguindo cumprir com seu objetivo de preparar o profissional para lidar com esse tipo de situação.

Em revisão de literatura sobre os cursos de tanatologia, Kovács ${ }^{12}$ conclui que existe uma valorização dos aspectos objetivos e científicos nesses cursos; no entanto, não existe espaço para lidar com os sentimentos e emoções desencadeadas pelo tema, não se desenvolvem habilidades interpessoais que são de grande importância na relação profissional - paciente - família e, principalmente, não existe uma preocupação com o fortalecimento pessoal do futuro profissional.

Por outro lado, Siqueira ${ }^{15}$ discute que mudanças curriculares no curso de medicina devem ser paradigmáticas e não programáticas: $o$ imprescindível são as transformações paradigmáticas, e não simplesmente remendos ou inserções de temas no programa ora vigente.

Vale ressaltar que a deficiência na formação profissional pode ser um determinante importante que interfere na maneira como os profissionais da saúde entendem e lidam com a morte. No entanto, não podemos considerá-lo como único.

Quando Leontiev ${ }^{6}$ afirma que a consciência é o reflexo da realidade, é preciso considerar que todo reflexo psíquico resulta de uma relação ação, de uma interação real entre um sujeito material vivo, altamente organizado e a realidade material que o cerca. Assumimos que a realidade que o cerca vai além da formação profissional, mas não podemos dissociar educação e sociedade. Isso porque, numa relação dialética, ao mesmo tempo em que a educação é determinada pela socie- 
dade, é através do processo educativo que acontece a apropriação do conhecimento produzido historicamente, a formação da humanidade em cada indivíduo e a transformação da cultura e da sociedade ${ }^{16}$.

Defendemos a formação do profissional da saúde para lidar com a morte justamente porque compartilhamos do entendimento de Vigotski ${ }^{17}$ quando afirma que a meta da educação não é a adaptação ao ambiente já existente, [...] mas a criação de um ser humano que olhe para além de seu meio. No caso do tema dessa pesquisa, especificamente, o olhar do profissional da saúde deve extrapolar a morte medicalizada e alcançar o cuidado para a boa morte.

Várias pesquisas ${ }^{18}$ enfatizam o aspecto simbólico e emocional no processo de doença e cura, justificando a necessidade de um novo paradigma para a saúde, que incorpore tanto a tecnologia e o saber acumulados historicamente como um sentido mais humano de se lidar com as emoções e o cuidado.

$\mathrm{Na}$ presente pesquisa, apenas dois enfermeiros relataram que a formação em relação à morte esteve presente em várias disciplinas e sentem-se satisfeitos com essa formação. Mesmo assim, um deles entende que a função do profissional da saúde neste contexto de trabalho não é cuidar do paciente, e sim não deixar [o paciente] morrer (E2).

Se o profissional da saúde tem uma formação essencialmente técnica, não desenvolvendo estratégias de enfrentamento para lidar com o processo de morte e, além disso, aprende que sua função é salvar o paciente a qualquer custo, torna-se compreensível que, atrás da representação social da morte como processo biológico, o verdadeiro sentido da finitude do ser humano seja de fracasso e impotência:

A morte é o fim da vida e assim, em alguns casos, é um fracasso da minha parte M5

Diante da percepção de fracasso e impotência do profissional em relação à morte, parece se estabelecer uma de negociação de saberes diante da morte, afirmando-a como uma bênção divina.

Rodrigues ${ }^{19}$ confirma que, diante da percepção da incapacidade humana, uma das maneiras da medicina entender e lidar com a morte foi justamente sua compreensão como bênção divina ou vontade de Deus.

Pensar que foi Deus quem quis a morte (E3, M1) ou era a hora da morte (E2, E4, M2, M4, M5) ou a pessoa vai para um lugar melhor (M1, M6) protege o profissional, que não aprendeu a lidar com o processo de morte, da angústia gerada pela percepção consciente da morte.
A gente sempre coloca Deus junto: [...] 'Eu faço, mas Você [Deus] resolve se vive ou não'; não sou eu M2

Então, alguém queria que ele fosse, era a hora [...] Cumpriu o que tinha que cumprir na terra. A gente parte pra esse lado, porque a gente não tem explicação, né? M5

Mesmo apelando para uma explicação espiritual para a morte, percebe-se que nossos profissionais ainda não se sentem totalmente confortáveis e convencidos. Nesse sentido, estabelece-se uma contradição, na qual o sentido de finitude do ser humano passa a ser de algo que não pode ser processado pela razão.

Eu não acho fácil [lidar com a morte]. Talvez pelo medo de não saber o que tem depois disso [...] No fundo, no fundo, você sempre fica com uma duvidazinha E5

Assim, a concepção mencionada pode estar relacionada a um processo de alienação. De acordo com Montero ${ }^{20}$, com base na concepção marxista, esse processo acontece quando a atividade e o seu resultado são independentes, sendo o produto final estranho ao trabalhador. Duas formas de alienação podem estar presentes aqui: o sentimento de falta de poder (impotência) e o autoestranhamento (crença na existência de outros poderes gerando passividade no indivíduo); ou seja, coloca-se num plano externo a responsabilidade da própria atividade, perdendo o profissional o controle sobre ela. A superação dessa alienação torna-se possível apenas à medida que os indivíduos puderem retomar para si o controle consciente das transformações das circunstâncias e de si mesmos ${ }^{21}$.

Ainda que, em última instância, não seja possível transformar a circunstância da morte, é preciso transformar a si e a sua atividade, através da maneira de lidar e entender o processo de morte.

Os Cuidados Paliativos, através dos seus pressupostos básicos (assistência integral à pessoa e seus familiares; direito à qualidade de vida e autonomia no processo de morte; valorização da sensibilidade, relação interpessoal e expressão de emoções ${ }^{22}$ ), podem ser uma alternativa aos profissionais que se deparam com os processos de morte no cotidiano de trabalho.

Além disso, poderia contribuir para a transformação do profissional e da atividade em saúde a elaboração e a implantação de políticas de saúde e educação em saúde sobre o cuidado integral no processo de morrer, através de um intenso debate e da inclusão desse tema como objeto de estudo e intervenção da Saúde Coletiva ${ }^{23-26}$.

Com a deficiência na formação profissional e a dificuldade de lidar com a finitude do ser hu- 
mano, referir-se a Deus ou a questões espirituais para explicar a morte torna-se uma maneira de minimizar o sentimento de culpa diante da sensação de fracasso e impotência e/ou explicar aquilo que, através da ciência, não foi possível explicar ou não se quer aceitar.

Considerando que a forma superior de comunicação do homem reflete a realidade de modo generalizado ${ }^{5}$, a finitude do ser humano enquanto unidade de análise inclui não apenas a morte como consequência da vida, processo biológico ou bênção divina, mas também, ainda que oculto, a morte como perda e negação; como fracasso, como impotência e como culpa do profissional; assim como uma explicação daquilo que a ciência não explica ou não aceita.

A análise baseada no método proposto por Vigotski ${ }^{5}$ engloba ao mesmo tempo aspectos cognitivos/intelectuais e aspectos afetivos da ideia. De acordo com este autor, existe um sistema semântico dinâmico que representa a unidade dos processos afetivos e intelectuais, que em toda ideia existe, em forma elaborada, uma relação afetiva do homem com a realidade representada nessa ideia.

Falar da finitude do ser humano, portanto, envolve falar não só dos aspectos técnicos da morte (fim das funções encefálicas) como também dos aspectos afetivos / emocionais (tristeza, separação, saudade).

A articulação entre consciência e afetividade é fundamental no processo de análise, principalmente tratando-se da temática desta pesquisa. Vigotski ${ }^{5}$ inclusive faz uma crítica à psicologia tradicional por separar consciência e afeto: $A$ separação entre a parte intelectual da nossa consciência e a sua parte afetiva e volitiva é um dos defeitos radicais de toda a psicologia tradicional [...] Quem separou desde o início o pensamento do afeto fechou definitivamente para si mesmo o caminho para a explicação das causas do próprio pensamento, porque a análise determinista do pensamento pressupõe necessariamente a revelação dos motivos, necessidades, interesses, motivações e tendências motrizes do pensamento.

Portanto, a afetividade tem uma importante contribuição nessa análise, no sentido de que só se torna possível a compreensão efetiva e plena do pensamento alheio [...] quando descobrimos a sua eficaz causa profunda afetivo-volitiva ${ }^{5}$.

\section{Considerações finais}

O método de análise proposto por Vigotski busca o significado da palavra, sendo este observado como unidade do pensamento e, ao mesmo tempo, da linguagem. Para isso, não basta entender a palavra isoladamente, é preciso compreender a origem e as relações que determinaram a construção social de seu significado e sentido; assim como o seu processo de desenvolvimento, o contexto em que ela se tornou prevalente e as contradições e transformações que sofreram. Contemplar o conjunto dessas perspectivas significa, no pensamento de Vigotski, apreender o fenômeno psicológico em sua totalidade.

A partir desse método utilizado na análise da concepção de morte para profissionais da saúde que trabalham em uma Unidade de Terapia Intensiva, podemos afirmar que o profissional encontra dificuldade para lidar com situações de terminalidade da vida, inclusive sentindo-se culpado, em alguns casos, pela morte do paciente. Tal situação pode estar relacionada à deficiência na formação profissional e ao paradigma científico que impõe como regra a obstinação pela cura do paciente, responsabilizando o profissional pelo sucesso ou fracasso desta função.

Trata-se de uma formação que conduz o profissional a um processo de alienação, impondo explicações espirituais àquilo que foi negligenciado e até ironizado durante sua formação: a afetividade do profissional que também sente e sofre com a morte e a perda.

A formação tecnicista, vinculada ao modelo biomédico, promove a manipulação do corpo, mas não o cuidado de si e do outro, principalmente em seu âmbito emocional. Tal formação, que não está desvinculada do contexto sócio-cultural mais amplo, pode dificultar a maneira do profissional compreender o processo de morte e, consequentemente, prejudicar o cuidado do paciente.

A finitude do ser humano como unidade de análise da concepção de morte incorpora, assim, a necessidade de mudança no paradigma da ciência do cuidado e, a priorização da educação sobre a morte e o morrer no processo de formação profissional e no contexto institucional.

Este novo paradigma poderia favorecer, nas organizações de trabalho da área de saúde, a educação permanente sobre a morte e o morrer, tendo em vista a construção de novos sentidos e maneiras de atuação profissional (e não apenas novos discursos) que valorizem a dignidade humana e a qualidade de vida de pacientes, familia- 
res e trabalhadores. Embora iniciativas pontuais sejam valorizadas, a educação permanente do profissional da saúde no ambiente de trabalho deveria ser vinculada a uma política nacional de Educação Permanente em Saúde Coletiva.

Nesse sentido, a educação formal poderia transformar-se em um espaço de construção de novos sentidos sobre a morte, novas formas de intervenção sobre a realidade e, finalmente, um espaço que possibilite a superação da alienação e um desenvolvimento humano mais pleno. Para isso, não basta a inserção de novos conteúdos; é preciso articular conhecimento teórico-técnico com o desenvolvimento de habilidades e compe-

\section{Referências}

1. Ariès P. História da morte no ocidente. Rio de Janeiro: Ediouro; 2003.

2. Elias N. A solidão dos moribundos. Rio de Janeiro: Zahar; 2001.

3. Illich I. A expropriação da saúde: nêmesis da medicina. 2a ed. Rio de Janeiro: Nova Fronteira; 1975.

4. Prado SD, Sayd JD. A gerontologia como campo do conhecimento científico: conceito, interesses e projeto de medicina. Cien Saude Colet 2006; 11(2):491501.

5. Vigotski LS. A construção do pensamento e da linguagem. São Paulo: Martins Fontes; 2000.

6. Leontiev A. O desenvolvimento do psiquismo. Lisboa: Horizonte Universitário; 1978.

7. Lane STM. Usos e abusos do conceito de Representação Social. In: Spink MJP, organizadora. $O$ conhecimento no cotidiano: as representações sociais na perspectiva da psicologia social. São Paulo: Brasiliense; 1995. p. 58-72.

8. Conselho Nacional de Saúde. Resolução n. 196, de 10 de outubro de 1996. Brasília; 1996.

9. Malinowski B. Argonautas do Pacífico Ocidental. São Paulo: Abril Cultural; 1976.

10. Kovács MJ. Morte, separação, perdas, o processo de luto. In: Kovács MJ, organizadora. Morte e desenvolvimento humano. São Paulo: Casa do Psicólogo; 1992. p. 153-69.

11. Carvalho VA. A vida que há na morte. In: Bromberg MHPF, Kovács MJ, Carvalho MMMJ, Carvalho V, organizadores. Vida e morte: laços da existência. 2a ed. São Paulo: Casa do Psicólogo; 1996. p. 35-75.

12. Kovács MJ. Educação para a morte: um desafio na formação de profissionais de saúde e educação [tese]. São Paulo: Universidade de São Paulo; 2002.

13. Souza MTM, Lemonica L. Paciente terminal e médico capacitado: parceria pela qualidade de vida. Bioética 2003; 11(1):83-100.

14. Meleiro AMAS. O médico como paciente. São Paulo: Lemos Editorial; 1999. tências que privilegiam o sujeito, a subjetividade e o cuidado de si e do outro que se encontra em diferentes fases do desenvolvimento humano, inclusive no final da vida.

\section{Colaboradores}

DS Combinato e MS Queiróz participaram igualmente de todas as etapas da elaboração do artigo.
15. Siqueira JE. A arte perdida de cuidar. Bioética 2002; 10(2):89-106.

16. Saviani D. Pedagogia histórico-crítica: primeiras aproximações. 3a ed. São Paulo: Cortez, Autores Associados; 1991.

17. Vigotski, LS Psicologia pedagógica. Porto Alegre: Artmed; 2003.

18. Lèvi-Strauss C. Antropologia Estrutural. Rio de Janeiro: Tempo Brasileiro; 1970.

19. Rodrigues JC. O tabu da morte. $2^{\text {a }}$ ed. Rio de Janeiro: Fiocruz; 2006.

20. Montero M. El concepto de alienación en la dependencia. Aspectos psicológicos. In: Ideología, alienación y identidad nacional - una aproximación psicosocial al ser venezolano. Caracas: Ed. de la Biblioteca; 1991. p.57-70.

21. Martins LM. A natureza histórico-social da personalidade. Caderno CEDES 2004; 24(62):82-99.

22. Menezes RA. Em busca da boa morte: antropologia dos cuidados paliativos. Rio de Janeiro: Garamond Fiocruz; 2004.

23. Kovács MJ. Bioética nas questões da vida e da morte. Psico USP 2003; 14(2):115-167.

24. Torres WC. A Bioética e a psicologia da saúde: reflexões sobre questões de vida e morte. Psico Refle Crit 2003; 16(3):475-482.

25. Siqueira-Batista R, Schramm FR. A filosofia de Platão e o debate bioético sobre o fim da vida: interseções no campo da Saúde Pública. Cad Saude Publica 2004; 20(3): 855-865.

26. Rego S, Palácios M. A finitude humana e a saúde pública. Cad Saude Publica 2006; 22: 1755-1760.

Artigo apresentado em 08/04/2008

Aprovado em 21/08/2008

Versão final apresentada em 15/09/2008 